\title{
Exploring clinical practice and developing clinician self-reflection through cross self-confrontation methodology: an experimentation within an addiction medicine unit
}

Sophie Paroz ${ }^{1}$, Jean-Bernard Daeppen ${ }^{1}$, Martine Monnat ${ }^{2,3}$, Michael Saraga ${ }^{1}$, Francesco Panese ${ }^{1}$

\section{Keywords}

qualitative methodology; cross self-confrontation; addiction; substance use disorders; addictionrelated clinical practice; reflective practice.

${ }^{1}$ Lausanne University Hospital and University of Lausanne, Lausanne, Switzerland

${ }^{2}$ Lausanne University Hospital and University of Lausanne, Lausanne, Switzerland (retired)

${ }^{3}$ Public Health Service of Canton of Vaud, Lausanne, Switzerland (retired)

\section{Corresponding Author}

Sophie Paroz, Addictions medicine, Lausanne University Hospital and University of Lausanne, Rue du Bugnon 23, CH-1011 Lausanne, Switzerland.

Email: sophie.paroz@chuv.ch 


\begin{abstract}
Use of the methodology of cross self-confrontation (CSC) is limited in the field of medicine and previous research did not explore clinical practice in the context of clinical interview between clinician and patient. We experimented CSC within a qualitatively-driven mixed-method research aiming at exploring addiction-related clinical practice and related difficulties. CSC was part of a 3phase design based on video recorded clinical interviews with pairs of medical doctors and nurses from an addiction medicine unit of a university hospital. The current article presents a novel application of CSC in a clinical setting and illustrates the methodological process through one specific result. Findings suggest two major strengths of CSC in the context of medical research and education: the capacity to elicit tacit knowledge from daily clinical practice and the ability to enhance self-reflection by questioning professionals both individually and collectively. Further research on CSC in clinical surroundings should be encouraged.
\end{abstract}




\section{The call of cross self-confrontation methodology to explore clinical practice}

The social and human sciences are a constant source of inspiration for developing new approaches that best meet the fields of investigation of medical research. Within a research team in addiction medicine, we experimented a method used mainly in work psychology: the methodology of cross self-confrontation (CSC) (Clot, 2005; Clot, Faïta, Fernandez, \& Scheller, 2001; Clot \& Kostulski, 2011; Kloetzer, 2018; Kostulski \& Kloetzer, 2014). We used CSC as core component of a hospitalbased qualitatively-driven mixed-method design (Morse \& Cheek, 2014) that explored clinical addiction practice and related difficulties, as part of a discussion on the professionals' preparedness to respond to the needs of patients with substance use disorders.

The methodology of CSC emerged within the theoretical framework named "Activity Clinic" (Clot, 1999, 2001, 2009, 2011; Clot \& Kostulski, 2011; Kloetzer, Clot , \& Quillerou-Grivot 2018). Rooted in Vygotsky's works, this framework assumes that access to lived experience requires "indirect methods" based on the repetition of the experience (Clot, 2011; Vygotski, 2010 [1926]). In order to support the professionals through the analysis and the development of their work activity, the Activity Clinic designed various methodological strategies by shifting professional activities to a new context and using dialogical tools (Yves Clot, 2011). Basically, the method consists of inviting professionals to comment on sequences of their own video recorded activity in the presence of a researcher (simple self-confrontation interview, simple SCI), or a researcher and another professional (cross selfconfrontation interview, cross SCI). In the original theoretical approach, simple SCI and cross SCI are the second part of a 3-phase process that starts with the constitution of an analysis group and ends up with extended analyses by the original analysis group. CSC refers to the full process, although the method is mainly known for its second phase and the successive application of simple SCI and cross SCI.

CSC has been used in many professional contexts, ranging from technical diving (Kloetzer 2013) to preaching in homily (Kostulski 2014) and car manufacturing (Kloetzer 2018b). But as far as we 
know, its application within the fields of care and medicine is currently limited. One research explored the work conditions of nurses and assistant nurses in a geriatric care unit (Litim, 2006), and another explored changes in the profession among medical radiology technicians (Pires Jorge, 2016). Finally, an interesting study was conducted in the context of robotic surgery and evolving technology (Seppänen, Kloetzer, \& Riikonen, 2017) in an attempt to develop learning strategies for surgeons of a hospital oncology unit. These studies focused on medical professions or practices in evolving professional contexts and did not explore clinical practice in the context of intersubjective activity between clinician and patient.

Unlike previous research using CSC within the medical field, we applied CSC to examine the experience of care in a context of clinical interview with a patient. Our initial interest in using CSC within this specific context was to explore clinical practice through audiovisual data of professional activity and to trigger the thinking from the activity itself. By relying on video footage and requiring professionals to put their action into words, CSC was a way to "narrow the focus to what people are doing" and collect field-grounded knowledge about addiction clinical practice and related challenges (Barry, 2002, p.1094). Secondly, we intended to take advantage of the reflective process at the heart of CSC to produce scientific knowledge. Exploring clinical practice uncertainty (Fox, 1957; Mackintosh \& Armstrong, 2020) and addiction-related clinical practice complexity (O'Connor, Sokol, \& D'Onofrio, 2014) requires methodological strategies capable of questioning the knowledge, values and representations that underpin daily practices. CSC appeared to be one of these strategies. Finally, the performativity induced by CSC reflective process was of specific interest from a learning perspective and reminiscent of specific clinical educational contexts such as clinical supervision (Falender \& Shafranske, 2014; Owen \& Shohet, 2013). CSC's ability to reflect on one's actions in order to engage in a process of continuous learning and develop professional competencies was demonstrated in various environments (Kloetzer et al., 2018; 
Seppänen et al., 2017). Being able to observe the educational dimension in a setting with a long tradition of collaborative learning was an appealing concept.

By placing professionals in a situation of activity through audiovisual data and encouraging reflective capacity, we expected CSC to allow for a more in-depth analysis of clinical practice than typical qualitative data methods in medical research, such as semi-structured interviews and participant observation, and usual clinical educational contexts. Our aim in this article is to discuss the relevance of this experimental design in exploring and developing clinical practice. We present the methodology of CSC as applied within an addiction medicine unit. The adapted design will be shown, specific methodological steps will be detailed, the method will be illustrated through one specific result, and the conclusion will show several challenges encountered and comments addressing the application of CSC to research and education in clinical settings.

\section{The application of CSC within an addiction medicine unit: general design and material}

\section{Design}

The design implemented for this research (Table 1) was inspired by the Activity Clinic 3-phase design.

A research group was constituted in a preliminary phase (Pre-phase). It included medical doctors (two senior internist physicians and a senior psychiatrist) and researchers (qualitative researcher in addiction medicine and researcher in social studies of medicine) who shared an interest in exploring addiction-related clinical practice. General methodological options, including technical and ethical considerations related to the implementation of CSC in a clinical environment were discussed in the preliminary phase. Then a 3-phase process was repeated for each selected pair of clinicians.

Phase 1 included a research group meeting (1A) and two individual interviews between leading researcher and each clinician of one pair (Clinician 1, C1 and Clinician 2, C2) (1B and 1C). The 
purpose was to identify the activity to work on, anticipate organizational and technical implementation modalities and constitute the pairs.

\begin{tabular}{|c|c|c|c|}
\hline $\begin{array}{l}\text { Pre- } \\
\text { phase }\end{array}$ & \multicolumn{3}{|c|}{$\begin{array}{l}\text { Constitution of a research group } \\
\text { Development of general design } \\
\text { Definition of fields of investigation }\end{array}$} \\
\hline Phase 1 & \multicolumn{3}{|c|}{ DEVELOPING } \\
\hline $1 \mathrm{~A}$ & \multicolumn{2}{|l|}{ Research group meeting } & \multirow{3}{*}{$\begin{array}{l}\text { Constitution of the pair of } \\
\text { professionals } \\
\text { Definition of target activity } \\
\text { Definition of implementation } \\
\text { modalities }\end{array}$} \\
\hline 1B & $\begin{array}{l}1^{\text {st }} \text { individual interview } \\
\text { with Clinician } 1\end{array}$ & $\begin{array}{l}1^{\text {st }} \text { individual interview } \\
\text { with Clinician } 2\end{array}$ & \\
\hline $1 \mathrm{C}$ & $\begin{array}{l}2^{\text {nd }} \text { individual interview } \\
\text { with Clinician } 1\end{array}$ & $\begin{array}{l}2^{\text {nd }} \text { individual interview } \\
\text { with Clinician } 1\end{array}$ & \\
\hline Phase 2 & \multicolumn{3}{|c|}{ VIDEOING AND CONFRONTING } \\
\hline $2 \mathrm{~A}$ & Clinical interview 1 & Clinical interview 2 & $\begin{array}{l}\text { Video recording of target } \\
\text { activity }\end{array}$ \\
\hline 2B & $\begin{array}{l}\text { Video montage of } \\
\text { Clinical interview } 1\end{array}$ & $\begin{array}{l}\text { Video montage of } \\
\text { Clinical interview } 2\end{array}$ & $\begin{array}{l}\text { Video editing of clinical } \\
\text { interviews }\end{array}$ \\
\hline $2 \mathrm{C}$ & $\begin{array}{l}\text { Simple SCI } \\
\text { with Clinician } 1\end{array}$ & $\begin{array}{l}\text { Simple SCI } \\
\text { with Clinician } 2\end{array}$ & $\begin{array}{l}\text { Video recording of } \\
\text { confrontation of each } \\
\text { professional to own activity }\end{array}$ \\
\hline $2 \mathrm{D}$ & \multicolumn{2}{|c|}{$\begin{array}{l}\text { Cross SCI } \\
\text { with Clinician } 1 \text { and Clinician } 2\end{array}$} & $\begin{array}{l}\text { Video recording of } \\
\text { confrontation of each } \\
\text { professional to own activity in } \\
\text { the presence of a colleague }\end{array}$ \\
\hline $2 \mathrm{E}$ & \multicolumn{2}{|c|}{ Video montage of preliminary results } & $\begin{array}{l}\text { Video editing of complete } \\
\text { video recorded material }\end{array}$ \\
\hline Phase 3 & \multicolumn{3}{|l|}{ RESTITUING } \\
\hline $3 \mathrm{~A}$ & \multicolumn{2}{|c|}{$\begin{array}{l}\text { Group interview } \\
\text { with Clinician } 1 \text { and Clinician } 2\end{array}$} & $\begin{array}{l}\text { Restitution of preliminary } \\
\text { results to the pair } \\
\text { Further analysis and results } \\
\text { approval }\end{array}$ \\
\hline $3 \mathrm{~B}$ & \multicolumn{2}{|c|}{ Final video montage of results } & $\begin{array}{l}\text { Video editing of results based } \\
\text { on group discussion }\end{array}$ \\
\hline $3 \mathrm{C}$ & \multicolumn{2}{|l|}{ Feedback questionnaire } & $\begin{array}{l}\text { Participants' individual } \\
\text { feedback about CSC }\end{array}$ \\
\hline $3 \mathrm{D}$ & \multicolumn{2}{|l|}{ Research group meeting } & $\begin{array}{l}\text { Results restitution to the } \\
\text { research group } \\
\text { Results discussion }\end{array}$ \\
\hline $\begin{array}{l}\text { Post- } \\
\text { phase }\end{array}$ & \multicolumn{3}{|c|}{ Complementary research group meetings: pooling of results and further analysis } \\
\hline
\end{tabular}


Phase 2 was devoted to videoing and confrontation interviews. Each clinician video recorded himself/herself during a full clinical interview (2A). They were free to record any follow-up interview with any consenting patient presenting a substance use disorder that met the following criteria: no medical contraindication (e.g. severe pain or acute psychiatric disorders); no contraindication related to substance abuse (e.g. under the influence of drugs/alcohol or acute withdrawal symptoms) and sufficient command of the French language. Once the material was recorded, the researcher made a video montage out of selected sequences (2B, cf. p. 9) for Clinical interview 1 and Clinical interview 2. Video montages were used separately for each simple SCI (2C, cf. p.10) and then jointly for cross SCI (2D, cf. p.11). At this stage, to conclude Phase 2 and highlight preliminary results, the researcher edited a new video montage (2E) out of selected sequences from all recorded video material (cf. pp.11-12).

Phase 3 included results discussion, approval and restitution. The third video montage was discussed as part of an audio recorded group interview reuniting $\mathrm{C} 1$ and $\mathrm{C} 2$ and leading researcher (3A), and was finalized accordingly by the researcher (3B). To complete the results, a brief qualitative questionnaire was sent to $\mathrm{C} 1$ and $\mathrm{C} 2$ following group interview (3C, cf. p.12). Finally, extracts of final video montage were reported by the leading researcher to the research group and further discussed (3D). The entire results of Pair 1, Pair 2 and Pair 3 were discussed among the group researchers in a complementary phase (Post-phase).

\section{Recruitment}

The CSC component of our qualitatively-driven mixed method design included clinicians working in the outpatient consults of the hospital's addiction-specialized unit. According to CSC as proposed by Activity Clinic, pairs of professionals were of the same profession and same hierarchical level. All participants had to declare interest in analyzing their own practice. In addition, they had to meet the requirements of agreeing to video record a clinical interview, being available for a time-consuming project (estimated at approximately 8 hours over 2 months), and feeling comfortable pairing with a 
given colleague. Team leaders of outpatient consults were mobilized to submit a list of potential participants. The leading researcher assessed motivation and requirements fulfillment during individual interviews (1B). Once accepted, participants were interviewed again (1C) to discuss target activity, to share instructions and procedures, to discuss any question and to give formal consent. The first six professionals contacted to constitute the three pairs agreed to participate.

\section{Sample}

Three pairs of clinicians of the Addiction medicine unit of a Swiss university hospital took part in the research: two senior nurses of the liaison team (Pair 1); two psychiatry residents of the outpatient clinic (Pair 2); and two junior nurses of the opioid maintenance therapy program (Pair 3). Pairs were limited to three, due to the volume of collected data. Each pair went through the full 3-step design that lasted 4-5 months. The full process occurred between September 2017 and July 2019.

\section{Collected data}

Empirical data include written notes from six preliminary individual interviews, six video recorded clinical interviews and related verbatim transcriptions, six video montages of clinical interviews, six video recorded simple SCIs and related verbatim transcriptions, three video recorded cross SCIs and related verbatim transcriptions, three audio recorded group interviews and related verbatim transcriptions, qualitative data extracted from six questionnaires, and six video montages of pre-final and final results. Notes from six research group meetings and a complementary logbook complete the materials.

\section{Ethics}

On account of the use of material from clinical interviews, a study summary was submitted to the Cantonal Research Ethics Committee for approval. On April 11, 2017, it was decided that the research (Req-2017-00238) did not fall within the scope of application of the law on Research on Human Subjects and did not need to be submitted as part of the complete procedure. But at the request of the 
Committee, a series of measures were taken to protect direct (clinician) and indirect (patient) subjects. All Information and consent sheets were submitted and validated by the Committee.

\section{The application of CSC within an addiction medicine unit: a few steps in details}

\section{Recording and editing clinical interviews (Phase 2: $2 A$ and 2B, cf. Table 1)}

The recorded video activity is a full clinical interview, which features a clinician and a patient in dialogue. The clinical interviews were video recorded in the absence of researcher or cameraman in order to limit interference in clinical work. Video equipment (camera, tripod, and microphone) was made available to clinicians so they were free to record at any time; there was no time limit. The recording was taken to the researcher, along with a brief questionnaire detailing the date and context of the clinical interview, the rationale for choosing that particular interview and the description of any moment of the interview the clinician wanted to work on.

Original clinical interviews lasted 24-51 minutes. The researcher's first two full viewings ended in a clinical interview résumé, a list of covered topics (e.g. risk taking, pharmacology, life history, withdrawal symptoms) and a list of meaningful activities of the clinician (e.g. note taking, laughing or interrupting the patient). Recordings of clinical interviews were then shortened for use in simple SCIs and cross SCIs. The intention was less to select moments of the clinical interview considered to be more valuable for analysis than to transform the recorded work activity into an appropriate time format. As mentioned above, clinicians were free to select any sequence they decided on. Two clinicians asked for given sequences. The researcher then selected (complementary) sequences. The selection criteria were quite flexible but each video montage had to be representative of the various moments and topics covered in each interview. The reasons for those choices were documented for use in later analyses. Each video montage contained 4-6 sequences. Video montages lasted 10-12.5 minutes. 
The general intention of this interview is to lead the professional to think about what he/she is doing and to explicit narratively the reasons and conditions of the activity. The procedure was faithful to the original method: 1) the clinician watched the video montage of own clinical interview without interruption; 2) the clinician watched it a second time with these instructions: "Look and comment on what you do and how you do it. Show me what is important to you, challenges you, or surprises you when you see yourself working. You can stop the viewing as soon as something catches your attention"; 3) during the second viewing, the researcher stated reasons for selecting each sequence; 4) before and after the second viewing, the researcher checked whether the clinician wanted to review other sequences of the initial clinical interview. The full interview was available to review and discuss potential complementary sequences. The need to watch additional material emerged during discussion in two cases.

The researcher constantly centered the dialogue on the recorded activity. Interventions were limited to rephrasing the instructions, or possibly asking for clarification of a statement. To restore attention to the activity, the researcher would restart the video.

Simple SCIs were video recorded and lasted 56-81 minutes. The researcher was in the axis of the lens, but in reverse shot in order to frame the professional and the clinical interview montage from the front.

Cross self-confrontation interview (cross SCI) (Phase 2: 2D, cf. Table 1)

The general intention here was to establish a dialogue between professionals and make them aware of alternative ways of practicing, so as to facilitate the emergence of professional controversies (Clot, 2005; Kostulski \& Kloetzer, 2014). Still in line with the original method, cross SCI began with uninterrupted successive viewing of both video montages of clinical interviews. During the second viewing, the researcher invited each professional to comment on the colleague's activity as follows: 
"You will see your colleague video recorded clinical interview. You can stop the viewing as soon as something questions you, surprises you or is not clear to you". The researcher limited the interventions to questions aimed at enhancing the dialogue (e.g. "What leads you to ask this question?", "What do you think of what your colleague says?").

Cross SCIs were video recorded and lasted 86-103 minutes. The two clinicians were filmed from the front, on both sides of the screen that was playing montages 1 and 2 . The researcher was in reverse.

Data analysis (Phase 2: 2C, 2D, 2E and Phase 3: 3A, cf. Table 1)

Data collection and analysis are fully articulated in CSC. By having professionals interpret their own clinical activity or that of their colleague, or by intervening on researcher's preliminary results, clinicians fully contributed to the analysis process throughout the different interview settings. The researcher was responsible for outlining preliminary results from recorded simple SCIs and cross SCIs. An analysis protocol was used for each recorded interview: 1) first viewing and writing an interview summary; 2) second viewing and describing the content of every intervention (i.e. moments during simple SCI or cross SCI when the clinicians stop the viewing to comment); 3) third viewing and open coding (Strauss \& Corbin, 1990) of the discourse; and 4) complementary reading of the interview transcripts. Then we highlighted: recurrent topics and expressed difficulties; discrepancies between the sequence selection criteria and topics covered when discussing the sequence; the evolution of the discourse; and apparent contradictions. Simple SCIs and cross SCIs were analyzed separately and jointly.

This stage of the analysis resulted in extracting emerging themes. A theme was defined as a specific difficulty encountered in addiction-related clinical practice, associated clinical challenges and any potential clinical responses to face it. A video montage of sequences from clinical interviews, simple SCIs and/or cross SCIs illustrated each theme. A written description of the different sequences that constituted a theme completed the montage. At this stage of the analysis, the researcher discussed the 
intermediate version of the results with each pair in an audio recorded group interview. One by one, each thematic sequence was viewed and discussed. Guiding questions were: Should this theme be part of the results? How could you clarify the related clinical challenges? Should we label the theme differently? Is there any other theme that should be part of the results? This stage of analysis resulted in a final editing that integrated clinicians' input.

Feedback questionnaire (Phase 3: 3C, Table 1)

A 5-item questionnaire focusing on the participants' experience and the impact of the experience on practice was added to the design. Questions were: What is your general feedback on this group research experience? What particular moment would you relate? To what extent have you thought about simple SCI/cross SCI in the context of your practice? Can you tell me about a clinical interview that has happened differently since this experience? and To what extent do you relate simple SCI/cross SCI and clinical supervision sessions? Pair 1 answered the questions at the end of group interview. The questionnaire was self-administered within one week of group interview for Pair 2 and Pair 3.

\section{An illustration, step by step}

The identified themes were diverse and included, for example, withdrawal symptoms, endangerment, value conflict, and influence of a substance on behavior. The present section focuses on one unique theme that emerged during the process: "disgust". This example is based on the experience of Pair 2 and was chosen since it illustrates well the emergence of the theme, step by step. Each step is illustrated through quotes from the initial recorded activity and the various types of interviews that followed.

\section{Step 2A: Clinical interview}

The second clinician of Pair 2 (C2) video recorded a follow-up clinical interview with a 56-year-old man with an alcohol use disorder. The patient $(\mathrm{P})$ visits the addiction outpatient clinic for the third 
time, following a hospital stay related to a traumatic injury and an episode of delirium tremens. The clinical interview lasts 40 mins. The video montage consists of 5 sequences (total 10 mins). Sequence 1 ( 2 mins, 33 secs) was selected by the researcher (RSR) because it occurred in the first phase of the interview and explored two subjects not yet addressed: the exploration of consumption past habits and the exploration of change.

At the start of Sequence 1, C2 explores the patient's alcohol consumption prior to his hospital stay. As the patient recounts his previous habits, C2 punctuates his patient's words by a simple "okay" (line 4).

1. P: Well, I used to start drinking at $6 \mathrm{pm}$.

2. C2: Okay. And this is a change in your consumption, that is to say before the hospital stay... that is to say that before the hospital stay you used to drink also during the day?

3. P: Ah yeah yeah! Before the hospital stay, I used to start the day with a whiskey shot. Because that was [P shows his throat with his hand], how can I say, what used to clear my throat the best.

4. C2: Okay.

5. P: So I used to start with a shot of whiskey and then after I used to drink my coffee and then after go shopping. At around 10am I used to open my bottle of Rosé [wine]. And I used to open my bottle of Red [wine] at around 7pm, there I used to eat, go to bed and that was it. And then it started again the next day.

\section{Step 2C: Simple SCI}

While viewing Sequence 1 of own clinical interview, C2 does not react while watching himself listen and consent to the patient's past consumption habits. He goes on watching the sequence and stops the recording to comment on his reaction when confronted with confused memories related to the patient's delirium tremens. 


\section{Step 2D: Cross SCI}

During cross SCI, C2's colleague (C1) watches and comments on the video montage of C2's clinical interview in the presence of C2. At Sequence 1, C1 stops the recording when C2 acknowledges the patient's story with a simple "okay" (line 4). She enhances C2's reaction, which she perceives as nonjudgmental, and explains alternative reactions that C2 could have had while listening to the patient's story. This passage is a turning point and the dialogue starts from there.

6. C1: But even this "okay", I find it very good. Because when he says that... well, he says he starts the day with a... by drinking whiskey. And then this is something that, well, it might surprise, it might disgust, it might make you judge, it might lead to many reactions. Well, he drinks whiskey as soon as he opens his eyes and then he drinks his coffee. Well, at the same time you say that he was very sick and that he was in intensive care. So this shows... This "okay", it's just that you have no judgment. Okay, your life was like that, your habits, this world thither. It seems very soothing to me to hear you.

C2 listens attentively and nods, but doesn't speak. The dialogue could have ended here. As if something was left aside in C1's first comment and C2's silence, the researcher relaunches the discussion by asking $\mathrm{C} 1$ about her own reaction during the viewing. $\mathrm{C} 1$ introduces the theme that will be at the heart of the following exchange by expressing her own reaction of disgust. Then she mentions again the specific moment where she interrupted the viewing and values once again her colleague's attitude and compares it to own reaction.

7. RSR: You talk about the reaction that could provoke these words. What was your own reaction?

8. $\mathrm{C} 1$ : By hearing, by observing?

9. RSR: Yes. 
10. C1: I was disgusted. I had the image, well the taste of whiskey, I mean how it can be to have the taste of whiskey for, as he says, "clear your throat". I mean the words he uses can be very physical. Uh... at 7 a.m. Well it was really almost a physical disgust when I heard that. And then, hearing C2 just say "okay", well I think it must be very calming for someone who is used to suffer.

Again, C2 listens and nods but does not react spontaneously. The researcher uses C1's comment to get $\mathrm{C} 2$ to react on the way he handles this part of the clinical interview. $\mathrm{C} 2$ briefly evokes a similar reaction to $\mathrm{C} 1$, without explicitly naming disgust.

11. RSR. What do you think about what C1 says? Does it mean anything to you?

12. C2. Yes. He is a patient...I understand that he can provoke this kind of reaction and I think that I... I had them [these reactions] myself. He's a very lonely patient, who is... who doesn't speak to anyone. At his place... I imagine it must be a little catastrophic in terms of hygiene. He is neglected, so this is it, I understand. That may provoke this [to be disgusted].

In order to follow up the discussion and focus on clinical practice, the researcher explored possible clinical responses to disgust. C2 and C1 present possible strategies.

13. RSR: How do we cope with disgust? [Long break. C1 and C2 raise their eyebrows]

14. C2: We want to make it conscious, to know ... how to recognize it.

15. C1: [We want] to tolerate it, first of all.

16. C2: And this, in a context of... vulnerability, fragility. It is disgusting because it is the disease, it is the deformity, it is... the decline. And then to tolerate it, too. In my opinion, every time we see a patient, it's a bit of a staging. We use our interpersonal skills and then we have to play a role of... to not play disgust. Yes, it is really as if we were actors but in the sense of... consenting to what the patient could... malleable tools, we are malleable for the patient. 
Then $\mathrm{C} 1$ choses to progress in the viewing of Sequence 1 and comments on the way C2 manages the patient's confused discourse related to his episode of delirium tremens. And after watching the full sequence, $\mathrm{C} 1$ reflects back to the delirium tremens. But her final comment returns to the beginning of Sequence 1 and her own reaction of disgust, as if she needed to explore it a little more.

17. C1 : Until now, I mean... only these two and a half minutes, it impresses me [to see] how much violence there is, after all. These are violent scenes, to walk among dying people, to believe that... to believe that he was dead. At the beginning also... I mean, all this disgust at the beginning. It's not easy, I imagine, to be in front of him.

Once again, the researcher uses $\mathrm{C} 1$ 's assumption to bring $\mathrm{C} 2$ back to the clinical interview and the initial activity. C2 goes further in recognizing his own disgust and acknowledges the difficulty in taking care of his patient. At that moment, $\mathrm{C} 1$ and $\mathrm{C} 2$ share a common clinical reality.

18. RSR: What do you think about what C2 says: "It's not easy to be in front of him"?

19. C2: I didn't expect to be in front of him, in the sense that I had also said that I didn't expect him to come for consultation. When he accepted the [medical] follow-up, I said to myself: Well, he's not going to come. Was it also a desire that he didn't come? [C2 smiles] And then I chose this patient a bit by default, he was the first who accepted [to be video recorded in the context of the research]. I wouldn't have chosen him as a model patient or as a patient I wanted to show off. I also recognize this repulsive aspect that he can have in what he says, in how he presents himself. So, I agree [that] it's not easy.

$\mathrm{C} 1$ goes on and generalizes $\mathrm{C} 2$ 's comment to all psychiatric and substance use disorder patients. Then she tries to explain more about her own disgust and related clinical difficulty. At this point, discourse on disgust evolves and indirectly addresses its moral dimension.

20. C1: But I get the impression, when you said before, well... that this is the majority of our patients. Patients who don't really appeal to us, who disgust us or say very violent things 
to us or very... Who disgust us in the sense that there is a lot of violence in what they experience. Also in all that is very physical in addiction... there are many things that are, in some ways, repulsive. Especially these patients that we meet... to get to intensive care it is necessary... that is to say they are also often in pronounced states of neglect.

One last time, the researcher brings $\mathrm{C} 2$ 's attention back to the initial clinical interview and makes him watch himself. By valuing his profession and more indirectly his work, $\mathrm{C} 2$ joins $\mathrm{C} 1$ 's initial valorization of his attitude (line 4); as if he realizes that he managed to overcome disgust. At this point, a transformation in the professional's perception of his activity happens.

21. RSR: And if I go back to what you said about this clinical interview and this patient: you said that you did not necessarily expect him to come, and that you maybe also did not want him to come. [C1 nods]. And then, in the end, when you see yourself working with him...

22. C2: Especially with the sentence that he says at the end, it touches me and it... Hmm, it makes me think it's... noble [C2 smiles], there is a nobility in this work. In the sense that I feel like this patient has little opportunity in his life to chat with someone like that. And then being there for that... being used for this... it is already useful in my opinion. It's very human, just the human contact. Therefore, to be able to overcome and be aware of that disgust and be there nevertheless, it is rewarding. What we do is noble, that's very romantic [C2 laughs].

After a brief silence, $\mathrm{C} 1$ restarts the video. Subsequent exchanges only concern other sequences.

\section{Step 3A: Group interview}

An initial analysis of the material collected with Pair 2 highlighted disgust as one of eight emerging themes. This result was presented to Pair 2 in the form of a video montage which depicted the evolution of discourse as we have just presented it in this section. The aim of the session was to co- 
approve this theme as a significant research result and to further elaborate related clinical challenges and responses.

After watching the montage, the pair validated the theme of disgust as a central difficulty in their clinical practice.

23. C1: I think it's [disgust] something that deserves to be in the central themes. Precisely because it is recurring, it is not just that patient.

A little further in the discussion, $\mathrm{C} 1$ evokes the trigger action in the clinical interview (line 4). This helps move away from disgust itself to identify more precisely the implied clinical challenges and required competences to deal with disgust: accepting disgust as part of clinical practice.

24. C1: And it's also, at the very beginning of the video sequence, it's also there... well we say it later too, how [can we] accept it all, how [can we] handle it all? Well, the fact that C2 says "okay", that's what we finally accept, working in these... that's the rules of the game after all, that it's gonna be disgusting, that it's gonna be violent. The question is how do we... live through as a therapist in front of... so that we can help them afterwards? [We must] already be able to say it, this "okay", without it being a lie. To really be able to say it honestly, that we are okay with that, it is already very demanding. And this is the prerequisite to be able to work afterwards, I think.

\section{Step 3C: Feedback questionnaire}

C2 directly alludes to this part of the process in the feedback questionnaire. He demonstrates the impact of the general process in terms of reflexivity and highlights the discussion on disgust as one relevant moment. The notion of "transparency" suggests that the methodological setting has allowed the emergence of a usually unspoken theme.

25. C2: The feedback is positive. The experience was very rich. Getting a reflection of one's own clinical activity allows to examine daily practice subtleties that otherwise escape us. 
These subtleties are of major importance because they are at the center of the relational issues that shape our practice. A particular moment: the discussion with $\mathrm{X}$ [C1] when watching my patient's video, where we discussed disgust with great transparency and clinical interest. It is a unique moment in everyday practice.

\section{Step 3D: Research group meeting}

Reporting this specific result to the research group had two outcomes. First, the discussion made it possible to better describe the emergence of this theme and to highlight the underlying methodological process. Second, the discussion initiated secondary analyses. The interpretation of disgust as a moral challenge initiated the development of a final system for categorizing emerging themes, which included moral challenges, epistemic challenges, technical challenges and institutional challenges as main categories.

\section{Comment on the illustration}

In our research, themes emerged in various dialogical configurations. In the example presented, dialogue starts in cross SCI with a compliment on a specific activity that departs from the initial reasons for selecting the sequence and the object of discussion during simple SCI. The compliment, by promoting one way of doing things, initiates the discussion. Then, by going back and forth to the initial activity and the trigger compliment, we assist in the "construction of a common object which was not given a priori by the film of the activity" (Kloetzer \& Henry, 2010, p.59), disgust. Little by little, we move from the recognition of disgust in a specific clinical situation to the recognition of disgust as a common addiction-related clinical difficulty. Progressively, we move from the initial mention of physical disgust to its moral dimension and related clinical issues. As the process goes on, awareness of disgust emerge, paving the way for alternative ways of thinking or acting in future daily activities. 


\section{Discussion}

\section{Challenges}

As members of the hospital and the medical research community, we took advantage of facilitated access to clinical settings and a large institutional network to implement this design. This connection facilitated specific methodological steps, such as recruitment of participants and anticipation of ethical issues specific to the use of highly confidential medical data. Further use and communication of results through the institution was also made easier. Despite these observations, experimenting with CSC in a clinical surrounding was challenging.

First, researchers have to deal with a particularly labor-intensive, time-consuming and complex methodological process. Coordinating the overall research, editing multiple video montages inbetween steps, combining use of audiovisual and written material and scheduling interviews and group meetings demands an inordinate amount of time and resources. Although we are used to working with qualitative material, we recognize that the amount of collected data for this project is impressive and out of step with the number of included participants. However, this challenge was partly related to a first use of CSC. Future application of the method will definitely be simplified.

Dealing with highly confidential material and medical data was a second challenge. Even though the patients were not the research participants, their formal consent was required, and patients' faces and voices have to be blurred for public presentations as for any research using medical data. Mostly, ethical considerations led us to select outpatient activities with a more confidential setting for video recording than inpatient activities (i.e. one patient per consultation room, closed consultation rooms, and no interference with daily hospital activity). Ethical considerations might restrict access to those portions of clinical activity involving patients, and must be considered in future research projects.

Another challenge concerned the use of CSC for those unfamiliar with the process. In contrast to other interview types based on dialogue between a researcher and a participant, such as 
confrontational interviews and deliberative interviews (Berner-Rodoreda et al., 2018), CSC exploration is based on a participant's dialogues with oneself and peers. Researchers must be able to partially withdraw and limit their interventions to generating dialogue instead of understanding it. During simple SCI and cross SCI, participants choose when to stop a video, which footage to focus on, and what part of the activities they wish to discuss. And during results restitution, they are free to reshape and label results in their own way. Researchers have to put aside part of their own questions, observations and interpretations, even though it seems most relevant to them at the time. The leading researcher experienced feeling a loss of control during the first two simple SCIs; she was reviewing video recorded activities without being free to point to her own questions. She simply had to trust the process, and stick to a path that was foreign to her. Her experience demonstrates the need to be particularly well-prepared and confident about how CSC interviews can be productive. As for the research results, they support that this challenge has been successfully completed.

One final challenge and perhaps the strangest part of adapting CSC to a clinical setting was to analyze an intersubjective activity between a professional and a patient by focusing on the professional's activity alone, while ignoring the patient's input and experience. In the approach proposed by the method, the clinician actively participates and positions himself. The patient is not included in the process, even though he/she is the very condition of the activity. Applying CSC to a clinical encounter made it hard not to be tempted to choose an alternative design that allows cross SCI between a clinician and a patient based on their common activity, namely the clinical interview. But this development, which echoes Wyer's interesting use of video-reflexive ethnography (Wyer et al., 2017), would introduce a significant departure from the original method. The professional-oriented approach of CSC is actually a major contribution, since it makes possible an exploration on clinical practice in terms of difficulties, uncertainties and moral challenges between peers. 


\section{Limitations}

Major limitations pertain to our adaptations from the original method as developed by the Activity

Clinic framework. A main one is the composition of our research group.

The group met the prerequisite of "building a collective of professionals around the concerns of the profession" (Kostulski, 2010, p.31), but it was not a collective of peers since hierarchical level and interdisciplinary standards were not representative of our clinician pairs. Our research included pairs of doctors and nurses. However, nurses were not included in the research group, which naturally limited interdisciplinary input and data discussion. We partially overcame this limitation by including nurses' input in the complementary data collection that preceded and followed the CSC component. However, future research should definitely pay attention to establishing an inclusive research group that is able to represent and express the interests of each.

Due to the complexity of organization in a clinical setting (irregular work schedules, clinical emergencies and frequent turnovers) and to the interdisciplinary and multi-site perspective that prevented collaboration with professionals from one unique field of practice, we gave up having a single analysis group that would bring together the three pairs as well as the researchers. Preliminary discussions and results restitutions were conducted separately within the research group and within each pair. The lead researcher was the liaison between the two groups. This particular departure from the original method relieved the system and facilitated the organization of meetings. But it represents the most evident adaptation compared to the original method, since the third phase of dialogue (group interviews) in our design is an extension of cross SCI rather than a new dialogical setting with a larger group of peers. This adaptation restricted the multiplicity of dialogical settings required by CSC and contributed to another limitation, i.e. participants' partial elevation to coresearcher status. As other contemporary methodological strategies that develop within a new politics of research participation and knowledge production (Cornwall \& Jewkes, 1995; Smit, Swartz, Bantjes, Roomaney, \& Coetzee, 2020), CSC claims a process of co-researching and 
associates researchers and professionals in a co-construction and co-analysis process (Clot, 2001; Kloetzer, 2018). Although the expected participation of clinicians was achieved during the first two phases, clinicians tended to be less involved when finalizing and approving results during group interviews. Sharing analyses with other pairs of professionals and returning results personally to the investigators may have improved distribution of the results and should be part of further use of CSC. As recommended by the original theoretical framework, CSC should also concentrate on areas where specific questioning is grounded and carried by field professionals from the start (Kostulski, 2010).

Overall, despite encountered challenges and limitations, experimental CSC in clinical encounters was very positive. Some strengths of the method and fields of application are presented below.

\section{Research perspectives: the emergence of tacit knowledge and alternative paths of action}

The main intention of this research was to explore addiction-related clinical practice and related clinical difficulties through a specific reflective activity based on audiovisual and grounded in the field material. Disgust is given as an example of the results. Disgust, as a clinical difficulty and its close connection with stigmatization and negative attitudes have been demonstrated within specific medical contexts (Finnell, 2018; Kaiser, Kohlen, \& Caine, 2019; Schnall, Haidt, Clore, \& Jordan, 2008; Vartanian, Trewartha, Beames, Azevedo, \& Vanman, 2018). The intervention of moral judgments in the clinical relationship (Hill, 2010), and more specifically in the fields of psychiatry and addiction medicine (Howard \& Chung, 2000; Shaw, 2004), is also documented. What we first retain from this specific illustration of results is that the opportunity to recognize disgust was created by the method, whereas it could have gone unnoticed.

Secondly, we retain that an opportunity is created by CSC to reflect on own clinical difficulties. Results emerge through a technique reminiscent of Schön's reflective model (Schön, 1983) by acknowledging the interaction between tacit knowledge and actions, and by bringing to the surface 
new understandings that shape our actions. The methodological process not only allowed to identify a moral sentiment (Smith, 2002 [1759]), but it also made it possible to understand how a moral sentiment induces a judgment and becomes a difficulty for clinical practice. Clinicians' awareness of disgust made it possible to reflect: on related clinical challenges (e.g. caring for a patient who disgusts us/that we judge); on own resources (e.g. recognition of own disgust/moral judgement and acceptation of disgust as part of clinical practice); and on alternative paths of action (e.g. "to say it, this "okay", without it being a lie", line 24) that clinicians can "embody in further actions" (Schön, 1983, p.50). Thus, one strength of the method was not only to allow the emergence of tacit clinical difficulties, but also to initiate a transformation of practice.

As expected, CSC probably provided access to information that would have escaped clinical interaction observations or the discourse on clinical practice, had it been a semi-structured interview. Most commonly used qualitative methods have great potentials in generating knowledge and interesting uses of these in the medical field have demonstrated, for example, the interest of participant observation for exploring clinical practice (Savage, 2000), the transformative potential of focus groups (Hyde, Howlett, Brady, \& Drennan, 2005) or the development of participant reflexivity through interview (Perera, 2020). However, our results supports that CSC heightened the reflective potential of the research process and favored access to "this "hard to say" with which we could maybe do something different than what we do" (Clot, 2005, p.43). Discussing insecurities, recognizing areas of incompetence and disclosing errors is particularly confronting for actors of modern medicine (LaDonna, Ginsburg, \& Watling, 2018; Rosenthal, 1995; Wu, 2000), whose core symbol is competence (DelVecchio Good, 1995). Voicing own counter-attitudes and moral challenges appears to be even more difficult (Kaiser et al., 2019; Martin, Lloyd, \& Singh, 2002) and requires adapted research or educational settings (Ballon \& Skinner, 2008; Skinner, Roche, Freeman, \& Mckinnon, 2009). CSC appears to be a good methodological strategy. At least, use of audiovisual empirical data allowed clinicians to focus on their own practice and to move away from general representations of 
addiction-related medicine. The method also led clinicians to recognize and take ownership of their difficulties and counter-attitudes. The results of our qualitatively-driven mixed method study (to be published), which includes semi-structured interviews with pairs of doctors and nurses from nonspecialized units, support these statements. Whereas clinicians reported the existence of moral judgements and conflict of values, these attitudes are poorly addressed and systematically attributed to colleagues.

The use of CSC appears to be particularly relevant for the field of addiction-related practice to explore lower regard for working with patients with substance use disorder and help clinicians question own relation to addiction. CSC may be of particular interest in any clinical setting with patients perceived as "difficult patients" (Koekkoek, Hutschemaekers, van Meijel, \& Schene, 2011), "dirty work patients" (Shaw, 2004) or "problem patients" (May \& Kelly, 1982), whatever the label, to work on own negative attitudes and stigmatizing reactions. More generally, CSC has the potential to elicit the unspoken part of clinical activity and is of specific interest for any research project that aims to explore values, social representations, hidden assumptions, unconscious bias, moral feelings or any other implicit knowledge that underlies the experience of care.

\section{Educational perspectives: a comparison with clinical supervision}

The results indirectly highlighted CSC's potential as an interesting practice-based learning setting and initiated a comparison with clinical supervision settings. By proposing a group reflective activity based on clinical material, CSC echoes various modalities of clinical supervision, such as peer supervision (Owen \& Shohet, 2013), Balint groups (Balint, 1957; Salinsky, Samuel, \& Suckling, 2006) or any other collaborative learning groups whose purpose is to discuss clinical challenges of every day practice based on the assumption that clinical practice uncertainty deserves "considered reflection" (Launer, 2015, p.473). The resemblance is based on a common understanding of the activity as "one of the possible activities in all of those that could have been or could be accomplished" (Clot, 2006, p.170), as well as a common intention to question daily activity 
and highlight alternative ways of practicing. Our experience of CSC confirmed these theoretical premises and helped clarify three distinctive features.

The first relates to temporality. CSC is based on a slow immersion consisting of distinct phases, distinct settings, change of protagonists, multiple viewings, and transition from video to written material. This differs from the more reactive temporality of clinical supervision. But mostly, while clinical supervision's reflective process evolves over time through a variety of new material that is reported when new clinical experiences arise, CSC remains focused on a single material over the whole reflective process. This difference is partly linked to the primary focus of each approach. In CSC, material reported in the form of clinical activity is first and foremost a methodological means taking the form of reflective support in a context of research with extendable temporality, whereas clinical supervision depends on a time-bound framework that meets a training objective.

The second distinctive feature relates to multiplicity. Changes of protagonists and multiplicity of dialogues are central in CSC. Use of dialogue between professionals to stimulate participant's inner dialogue (Kostulski \& Kloetzer, 2014) echoes individual and group clinical supervision. Similarly, cross SCI analysis of a person's way of acting through the eyes of a peer echoes group clinical supervision. However, there are some major differences; clinical supervision does not rely on a successive application of individual and group settings, whereas CSC takes advantage of crossing viewpoints. By diversifying settings and the recipients of dialogue, scrutiny on practice is renewed at each step. In our research, switching from the individual to the collective was the facilitator of the emergence of disgust, and brought to the forefront what the clinician had initially kept silent.

The third distinctive feature relates to expertise. CSC interviews are led by a researcher and aim at reinforcing learning by the peers (Kloetzer et al., 2018). CSC differs from clinical supervision because of the absence of an expert or a facilitator relying on his own professional experience in promoting reflective practice. In our research, the researcher was not invested as a representative of the clinical 
community and the profession's good practices; this probably favored a non-judgmental environment promoting dialogue regarding experience of care and related difficulties.

Observations of CSC as an educational tool in clinical settings suggest that CSC offers an interesting educational context to question practice and to improve self-reflection, which differs from clinical supervision in its various forms. Although it is difficult to document, the assumption is that CSC's temporality but mostly its multiplicity of dialogical settings will result in deeper self-reflection. And we believe that the absence of clinical expertise in discussions of clinical practice may lead to discussions of other issues that are not normally shared with clinical facilitators. However, the long term effectiveness of CSC compared to traditional clinical supervision settings has to be tested and the levels of reflection induced by the two processes have to be compared. Specific target audiences, particular fields of clinical practice and potential required adaptations so that it can be used easily in a learning context must also be defined. Formal experimentation and evaluation of CSC as a teaching vehicle for clinical practice are therefore encouraged.

\section{Concluding discussion}

The intention of this article was to report and discuss the experimentation of CSC in a specific clinical encounter. Through a specific process of co-analyzing video recorded clinical interviews, CSC made possible an exploration of addiction-related clinical difficulties experienced by hospital-based staff and stimulated self-reflection among clinicians.

We posit two major strengths: the method's capacity to question professionals both individually and collectively; and the capacity to elicit tacit knowledge of daily clinical practice. We believe the use of CSC is an opportunity for developing grounded, collaborative and performative research projects in clinical and hospital settings. We encourage further use of CSC in clinical encounters, as well as the formal evaluation of CSC in a clinical educational context. 


\section{Acknowledgements}

The authors wish to deeply thank the clinicians who took part in the research for their time and involvement in the study.

\section{Endnotes}

We conducted the interviews and clinical interviews in French. We translated the verbatim transcripts in English. Whenever necessary, we applied minor changes to ensure anonymity.

\section{References}

Balint, M. (1957). The Doctor, His Patient and the Illness. New York: International Universities Press.

Ballon, B. C., \& Skinner, W. (2008). "Attitude is a little thing that makes a big difference": reflection techniques for addiction psychiatry training. Acad Psychiatry, 32(3), 218-224. doi:10.1176/appi.ap.32.3.218

Barry, C. A. (2002). Multiple realities in a study of medical consultations. Qual Health Res, 12(8), 1093-1111. doi:10.1177/104973202129120467

Berner-Rodoreda, A., Bärnighausen, T., Kennedy, C., Brinkmann, S., Sarker, M., Wikler, D., .. . McMahon, S. A. (2018). From doxastic to epistemic: a typology and critique of qualitative interview styles. Qualitative Inquiry(1-15). doi:10.1177/1077800418810724

Clot, Y. (1999). La fonction psychologique du travail [Psychological function of work]. Paris: Presses universitaires de France.

Clot, Y. (2001). Méthodologie en clinique de l'activité. L'exemple du sosie. In M. Santiago Delefosse \& G. Rouan (Eds.), Les méthodes qualitatives en psychologie. Paris: Dunod.

Clot, Y. (2005). L'autoconfrontation croisée en analyse du travail: l'apport de la théorie bakhtinienne du dialogue In L. Filliettaz \& J. Bronckart (Eds.), L'analyse des actions et des discours en situation de travail. Concepts, méthodes et applications. Louvain: BCILL.

Clot, Y. (2006). Clinique du travail et clinique de l'activité. Nouvelle revue de psychosociologie, $1(1), 165-177$.

Clot, Y. (2009). Clinic of Activity: the dialogue as instrument. In A. Sannino, H. Daniels, \& K. Gutierrez (Eds.), Learning and expanding with activity Theiry (pp. pp 286-302): Cambridge University Press.

Clot, Y. (2011). Théorie en clinique de l'activité. In B. Maggi (Ed.), Interpréter l'agir : un défi théorique (Vol. Le travail humain, pp. 17-39): Presses Universitaires de France.

Clot, Y., Faïta, D., Fernandez, G., \& Scheller, L. (2001). Les entretiens en auto-confrontation croisée: Une méthode en clinique de l'activité [Cross self-confrontation interviews: A method in Activity Clinic] Education permanente,dossier: Clinique de l'activité et pouvoir d'agir, 146(1), 17-25. 
Clot, Y., \& Kostulski, K. (2011). Intervening for transforming: from activity to institution, an horizon of action in "clinic of activity" approach. Theory and Psychology, 21(5), 681-696.

Cornwall, A., \& Jewkes, R. (1995). What is participatory research? Soc Sci Med, 41(12), 16671676. doi:10.1016/0277-9536(95)00127-s

DelVecchio Good, M.-J. (1995). American Medicine: The Quest for Competence. Berkeley University of California Press.

Falender, C. A., \& Shafranske, E. P. (2014). Clinical supervision: the state of the art. Journal of Clinical Psychology, 70, 1030-1041.

Finnell, D. S. (2018). A call to action: Managing the neural pathway of disgust, bias, prejudice, and discrimination that fuels stigma. Subst Abus, 39(4), 399-403. doi:10.1080/08897077.2019.1576091

Fox, R. C. (1957). Training for uncertainty. In R. K. In Merton, Reader, G. and Kendall, P.L. (Ed.), The Student Physician. Cambridge: Harvard University Press.

Hill, T. E. (2010). How clinicians make (or avoid) moral judgments of patients: implications of the evidence for relationships and research. Philos Ethics Humanit Med, 5, 11. doi:10.1186/1747-5341-5-11

Howard, M. O., \& Chung, S. S. (2000). Nurses' attitudes toward substance misusers. I. Surveys. Subst Use Misuse, 35(3), 347-365. doi:10.3109/10826080009147701

Hyde, A., Howlett, E., Brady, D., \& Drennan, J. (2005). The focus group method: insights from focus group interviews on sexual health with adolescents. Soc Sci Med, 61(12), 2588-2599. doi:10.1016/j.socscimed.2005.04.040

Kaiser, M., Kohlen, H., \& Caine, V. (2019). Explorations of disgust: A narrative inquiry into the experiences of nurses working in palliative care. Nurs Inq, 26(3), e12290. doi: $10.1111 /$ nin. 12290

Kloetzer, L. (2018). Doing research upside down: Action and research in cross self-confrontations. International Journal of Action Research, 14(2+3), 202-218.

Kloetzer, L., Clot , Y., \& Quillerou-Grivot , E. (2018). Stimulating dialogue at work: The activity clinic approach to learning and development. In C. S. I. Publishing. (Ed.), Francophone Perspectives of Learning Through Work.

Kloetzer, L., \& Henry, M. (2010). Quand les instruments de métier deviennent objets de discours: une condition de l'analyse du travail en autoconfrontation croisée ? Activités, 7(2).

Koekkoek, B., Hutschemaekers, G., van Meijel, B., \& Schene, A. (2011). How do patients come to be seen as 'difficult'?: a mixed-methods study in community mental health care. Soc Sci Med, 72(4), 504-512. doi:10.1016/j.socscimed.2010.11.036

Kostulski, K. (2010). Quelles connaissances pour l'action en clinique du travail ? : une contribution à la question des rapports entre les actions de transformation et la production de connaissances en clinique du travail. In Y. Clot \& D. Lhuilier (Eds.), Agir en clinique du travail (pp. 27-38). Toulouse: ERES.

Kostulski, K., \& Kloetzer, L. (2014). Controversy as a development tool in cross self-confrontation analysis. Outlines-Critical Practice Studies, 15(2), 54-73.

LaDonna, K. A., Ginsburg, S., \& Watling, C. (2018). "Rising to the Level of Your Incompetence": What Physicians' Self-Assessment of Their Performance Reveals About the Imposter Syndrome in Medicine. Acad Med, 93(5), 763-768. doi:10.1097/ACM.0000000000002046 
Launer, J. (2015). Collaborative learning groups. Postgraduate Medical Journal, 91(1078), 473474.

Litim, M. (2006). Le diagnostic d'une activité complexe en gériatrie. Nouvelle revue de psychosociologie(1), 45.

Mackintosh, N., \& Armstrong, N. (2020). Understanding and managing uncertainty in health care: revisiting and advancing sociological contributions. Sociol Health Illn, 42 Suppl 1, 1-20. doi:10.1111/1467-9566.13160

Martin, J., Lloyd, M., \& Singh, S. (2002). Professional attitudes: can they be taught and assessed in medical education? Clin Med (Lond), 2(3), 217-223. doi:10.7861/clinmedicine.2-3-217

May, D., \& Kelly, M. P. (1982). Chancers, pests and poor wee souls: problems of legitimation in psychiatric nursing. Sociol Health Illn, 4(3), 279-301. doi:10.1111/1467-9566.ep10487972

Morse, J. M., \& Cheek, J. (2014). Making room for qualitatively-driven mixed-method research. Qual Health Res, 24(1), 3-5. doi:10.1177/1049732313513656

O'Connor, P. G., Sokol, R. J., \& D'Onofrio, G. (2014). Addiction medicine: the birth of a new discipline. JAMA Intern Med, 174(11), 1717-1718. doi:10.1001/jamainternmed.2014.4211

Owen, D., \& Shohet, R. (2013). Clinical supervision in the medical profession: structured reflective practice. Maidenhead: Open University Press.

Perera, K. (2020). The interview as an opportunity for participant reflexivity. Qualitative Research, 20(2), 143-159.

Pires Jorge, J. (2016). Technique et soin en radiologie médicale. Quand la professionnalité est empêchée. Carnets de recherche sur la formation [en ligne].

Rosenthal, M. M. (1995). The incompetent doctor. Behind closed doors. Buckingham: Open University Press.

Salinsky, J., Samuel, O., \& Suckling, S. (2006). Talking about my patient: the Balint approach in GP education. London: Royal College of General Practitioners.

Savage, J. (2000). Participative observation: standing in the shoes of others? Qual Health Res, 10(3), 324-339. doi:10.1177/104973200129118471

Schnall, S., Haidt, J., Clore, G. L., \& Jordan, A. H. (2008). Disgust as embodied moral judgment. Pers Soc Psychol Bull, 34(8), 1096-1109. doi:10.1177/0146167208317771

Schön, D. (1983). The reflective practitioner: how professionals think in action. New York: Basics Books.

Seppänen, L., Kloetzer, L., \& Riikonen, J. (2017). Encourager la réflexion en chirurgie robotique : l'autoconfrontation croisée comme instrument de développement du travail interprétatif dans un environnement technologique complexe [Enhancing productive reflection in robotic surgery: Cross self-confrontation as a developmental method for learning interpretativeness in a digitalized era work]. Psychologie du travail et des organisations(23), 117-136.

Shaw, I. (2004). Doctors, "dirty work" patients, and "revolving doors". Qual Health Res, 14(8), 1032-1045. doi:10.1177/1049732304265928

Skinner, N., Roche, A. M., Freeman, T., \& Mckinnon, A. (2009). Health professionals' attitudes towards AOD related work: Moving the traditional focus from education and training to organizational culture. Drugs: education, prevention and policy,, 16(3), 232-249. 
Smit, A., Swartz, L., Bantjes, J., Roomaney, R., \& Coetzee, B. (2020). Moving Beyond Text-andTalk in Qualitative Health Research: Methodological Considerations of Using Multiple Media for Data Collection. Qual Health Res, 1049732320976556. doi:10.1177/1049732320976556

Smith, A. (2002 [1759]). The Theory of Moral Sentiments. Cambridge Cambridge University Press.

Strauss, A., \& Corbin, J. (1990). Basics of Grounded Theory Methods : Techniques and procedures for developing grounded theory Newbury Park Sage.

Vartanian, L. R., Trewartha, T., Beames, J. R., Azevedo, S. M., \& Vanman, E. J. (2018). Physiological and self-reported disgust reactions to obesity. Cogn Emot, 32(3), 579-592. doi:10.1080/02699931.2017.1325728

Vygotski, L. (2010 [1926]). La signification historique de la crise en psychologie. Paris: La Dispute.

Wu, A. W. (2000). Medical error: the second victim. The doctor who makes the mistake needs help too. $B M J, 320$ (7237), 726-727. doi:10.1136/bmj.320.7237.726

Wyer, M., Iedema, R., Hor, S.-Y., Jorm, C., Hooker, C., \& Gilbert, G. L. (2017). Patient Involvement Can Affect Clinicians' Perspectives and Practices of Infection Prevention and Control: A "Post-Qualitative" Study Using Video-Reflexive Ethnography. International Journal of Qualitative Methods, 16, 1-10. 